\title{
Performance Investigation of the Solar Chimney Power Plants Heater Case Study in Aswan, Egypt
}

\author{
Magdy Bassily Hanna1, Tarek Abdel-Malak Mekhail'2, Omar Mohamed Dahab3, \\ Mohamed Fathy Cidek Esmail'2, Ahmed Rekaby Abdel-Rahman ${ }^{*}$
}

\author{
${ }^{1}$ Mechanical Power and Energy Department, Faculty of Engineering, Minia University, Minia, Egypt \\ ${ }^{2}$ Mechanical Power Department, Faculty of Energy Engineering, Aswan University, Aswan, Egypt \\ ${ }^{3}$ Mechanical Power Department, Faculty of Engineering, Aswan University, Aswan, Egypt \\ Email: *ahrk60@yahoo.com
}

How to cite this paper: Hanna, M.B., Mekhail, T.A.-M., Dahab, O.M., Esmail, M.F.C. and Abdel-Rahman, A.R. (2016) Performance Investigation of the Solar Chimney Power Plants Heater Case Study in Aswan, Egypt. Journal of Power and Energy Engineering, 4, 39-60.

http://dx.doi.org/10.4236/jpee.2016.410003

Received: September 20, 2016

Accepted: October 24, 2016

Published: October 27, 2016

Copyright $\odot 2016$ by authors and Scientific Research Publishing Inc. This work is licensed under the Creative Commons Attribution International License (CC BY 4.0).

http://creativecommons.org/licenses/by/4.0/
Open Access

\section{Abstract}

Solar collector is a thermal device that uses the heated air in the power generation and many engineering applications. The purpose of the present work is to study the performance and temperature distribution for the solar collector which uses heated air in solar chimney power generation that it consist of three parts, a turbine-generator unit which is used in the generation of electric energy, and cylindrical chimney is fixed vertically and finally a solar collector under the climatic conditions of EgyptAswan is studied. This site is specified as the hottest site because the nearest of this location from the Tropic of cancer. Experiments are performed in ten summer days of May and June 2015 with different solar radiations and clarity of the sky. Hourly values of global solar radiation and some meteorological data (temperature, pressure, velocity, etc.) for measuring days are obtained by measuring devices. Inlet and outlet temperatures of air from a solar collector and velocity at junction region. In this work, attempt has been made to present the effect of environmental factors such as ambient temperature, the clarity of the sky and solar radiation on the performance of solar collector. The temperature of the base and the cover of the solar collector, the variation of solar radiation, solar collector efficiency, heat transfer coefficient, the velocity at the junction region between the chimney base, the outlet of the solar collector and temperature distribution along the air heater are discussed. A prediction for the results of the solar collector were performed by using developed theoretical model was made by this study which is based on the previous works. The numerical study has used a commercial code CFX, ANSYS 16.1 to simulate the flow through the collector. The study show that the outlet air temperatures from the solar collector and the velocity at the junction are depending on the climate condition such as ambient temperature and solar radiation, the differences in air temperature at the solar collector ranging between $8^{\circ}-24^{\circ}$. It is concluded that the theoretical model is basi- 
cally valid for the system under study, and theCFD simulation can be used conveniently to predict the performance of the system, the comparison between them and experimental result shows a good agreement.

\section{Keywords}

Solar Chimney, Solar Collector, Natural Convection, Computational Fluid Dynamic

\section{Introduction}

Solar chimney is a simple and modern energy source also classified as efficient solar power technology. The Solar Chimney Power Plant system represents a possibility for the use of solar energy as a clean energy. As shown in Figure 1, the technology consists of three components: a solar collector, a cylindrical chimney and turbine-generator [1]. In the collector, solar radiation is used to heat the ground (ordinary soil), and then a large body of air, heated by the heat transfer from the ground, rises up the chimney, due to the density difference of air between the chimney entrance and the chimney outlet. The rising air drives large turbines installed at the chimney base to generate electricity power. The concept of solar chimney power technology was first purposed many years ago, again presented in 1978 and proven with the operation of a pilot 50

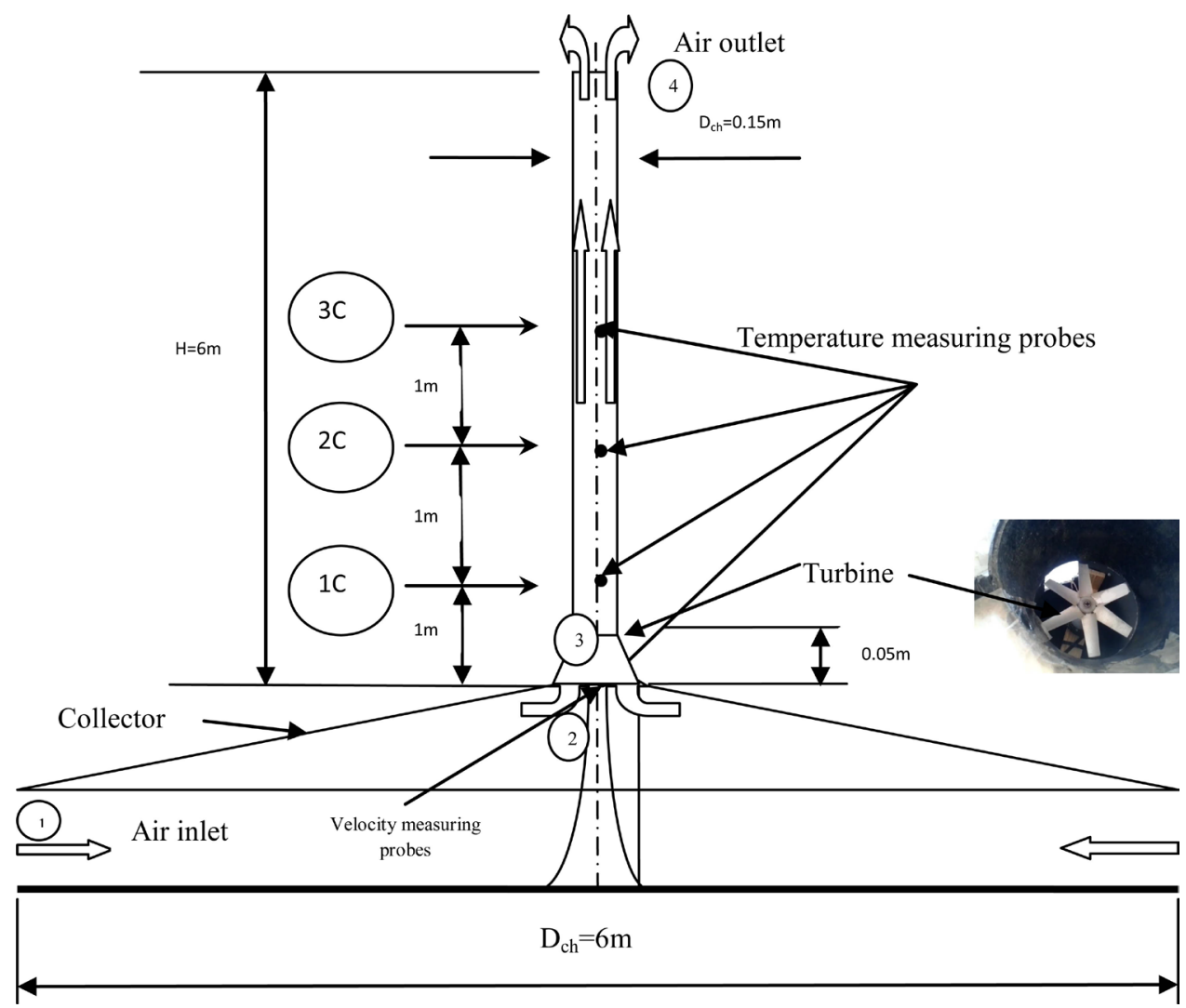

Figure 1. Schematic diagram of a solar chimney power plant. 
$\mathrm{kW}$ power plant in Manzanares, Spain in the early 1980s [2].

The SCPP which is a kind of renewable energy technologies was first proposed by professor Jörg Schlaich [1] and tested with a prototype model in Manzanares, Spain in the early 1980s. Haaf et al. [2] discussed the basic principles, energy balance, construction and cost analysis of a solar chimney power plant.

Most existing publications, mainly studied certain aspects of an SCPP with turbine. Backström and Gannon [3] further investigated the solar chimney turbine characteristics based on theoretical analysis and experimental data, and found that a peak turbine total-to-total efficiency of around $90 \%$ was attainable.

Kirstein and von Backström [4] studied the flow through the collector to a chimney transition section of a SCPP system, and developed semi-empirical formulas to predict flow loss coefficient in the transition section. Some heat transfer coefficients applicable to the SCPP collector were compared by Bernardes et al. [5]. They found that similar temperature profiles of the airflow and similar produced power could be obtained, despite the different approaches adopted. The ratio of pressure drop across the turbine to the total pressure difference available in the system was investigated by some researchers [5] [6] [7].

There are many other studies carried out with small-sized physical models constructed on-site. Krisst (1983) [8] built a solar tower setup of $10 \mathrm{~W}$ in Connecticut, USA, with its collector of $6 \mathrm{~m}$ diameter and $10 \mathrm{~m}$ height. Kulunk (1985) [9] demonstrated a plant with $9 \mathrm{~m}^{2}$ collector and $2 \mathrm{~m}$ high tower of $3.5 \mathrm{~cm}$ radius with power output of $0.14 \mathrm{~W}$ in Izmit, Turkey. Pasumarthi and Sherif (1998) [10] developed an approximate mathematical model for a solar tower plant and followed with a subsequent article (Pasumarthi and Sherif, 1998) [11] validating the model against experimental results from small-scale plant models in the University of Florida. In particular, the influence of various geometrical configurations on the performance and efficiency is investigated. Zhou et al. (2007) [12] built a pilot experimental setup in China with $10 \mathrm{~m}$ roof diameter and $8 \mathrm{~m}$ tower height and $0.3 \mathrm{~m}$ diameter, with a rated power of $50 \mathrm{~W}$.

In this paper, a detailed investigation of the performance for a solar collector as apart from the solar chimney power plant using experimentally, developed mathematical and numerical models are carried out to analyze the temperature field inside the collector, heat transfer coefficient, heat added and the velocity at the junction region between the outlet section of the solar collector and the chimney base in the meteorological site Aswan, Egypt.

\section{Test Rig and Measuring Instruments}

In order to evaluate the performance of solar collector as apart of solar chimney power plant, the experimental test rig was constructed in Faculty of Energy Engineering, Aswan University, and Aswan, Egypt as shown in Figure 1. Thesolar collector with $6 \mathrm{~m}$ diameter and a chimney with $6 \mathrm{~m}$ height, it was fixed vertically at the high of the solar collector center and made from PVC pipe with a diameter of $0.15 \mathrm{~m}$. The solar collec- 
tor frame was constructed from iron beams with wooden wired network use to support a clear plastic cover as shown in Figure 2. The solar collector cover was designed with inclination to allow water drainage in the event of rain and it could absorb the maximum solar radiation.

The height of the solar collector cover is slowly increasing with inclination along the radius from the outer $\operatorname{rim}(0.25 \mathrm{~m})$ to the inner rim of the solar collector $(0.5 \mathrm{~m})$ to minimize the friction losses and make the air slowly to accept more hat inside the solar collector under green house effect. A cross-sectional view of the solar collector is shown in Figure 3. This plastic roof allows the transmission of the short wavelength solar radiation but blocks the longer wave length radiation emitted by the ground. As a result, the ground under the roof heats up, which, in turn, heats the air flowing radially above it.

\section{Measuring Instrument}

Variable measurements Point's distributions for the in the solar collector were shown in Figure 3. The temperatures distribution of the air inside the solar collector were located at the vertical sections B, C, D and E, with the point 1, 2, 3, point A represents the inlet air temperature. Velocity measurement locations can be shown at section $\mathrm{E}$ with point E1, E2, E3 and 2 at the base of the chimney.

The temperatures of the air in the solar collector are measured using thermocouples data accusation card (Daq-2005) works with several types of thermocouples which has

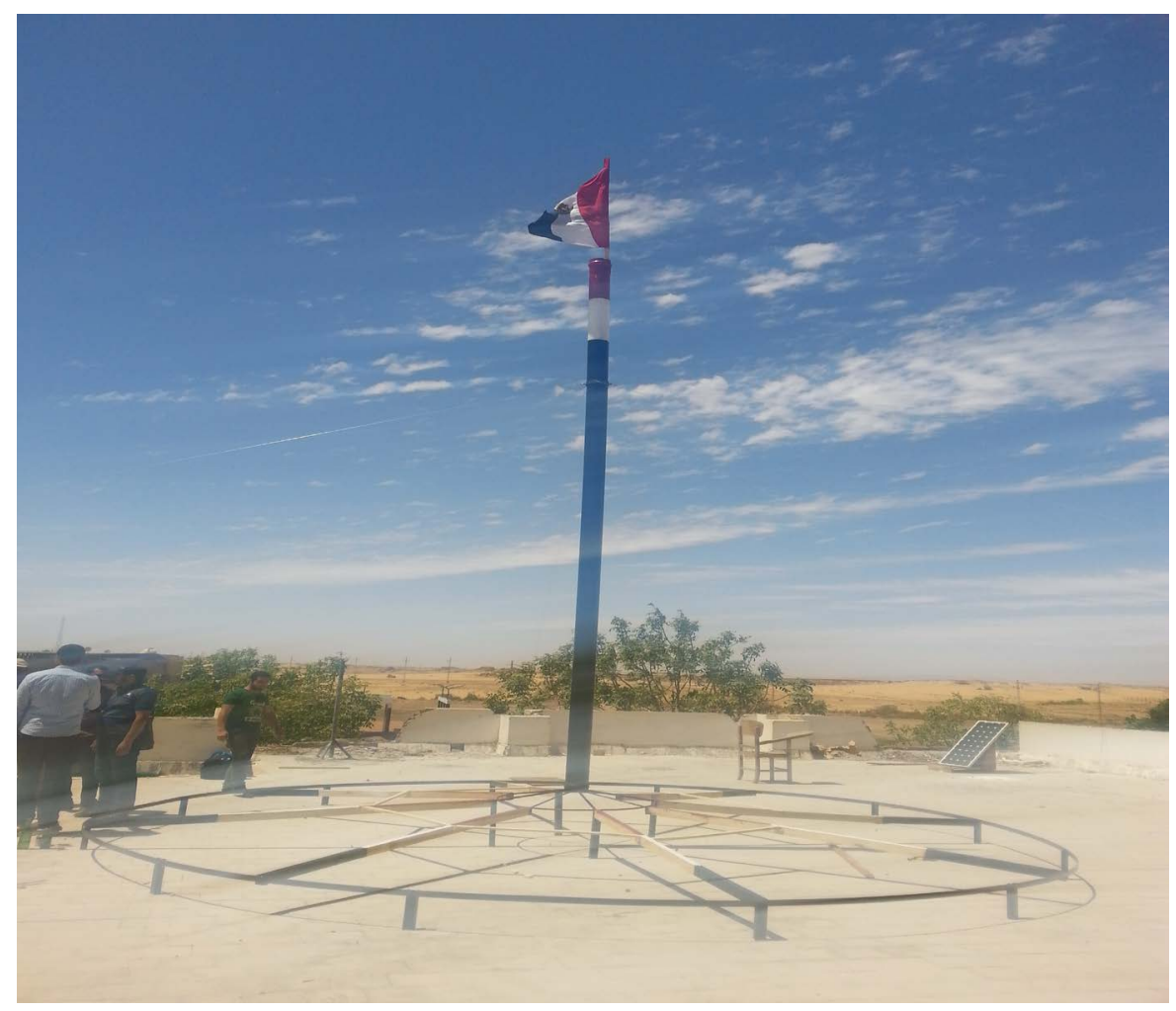

Figure 2. Construction of a solar collector. 


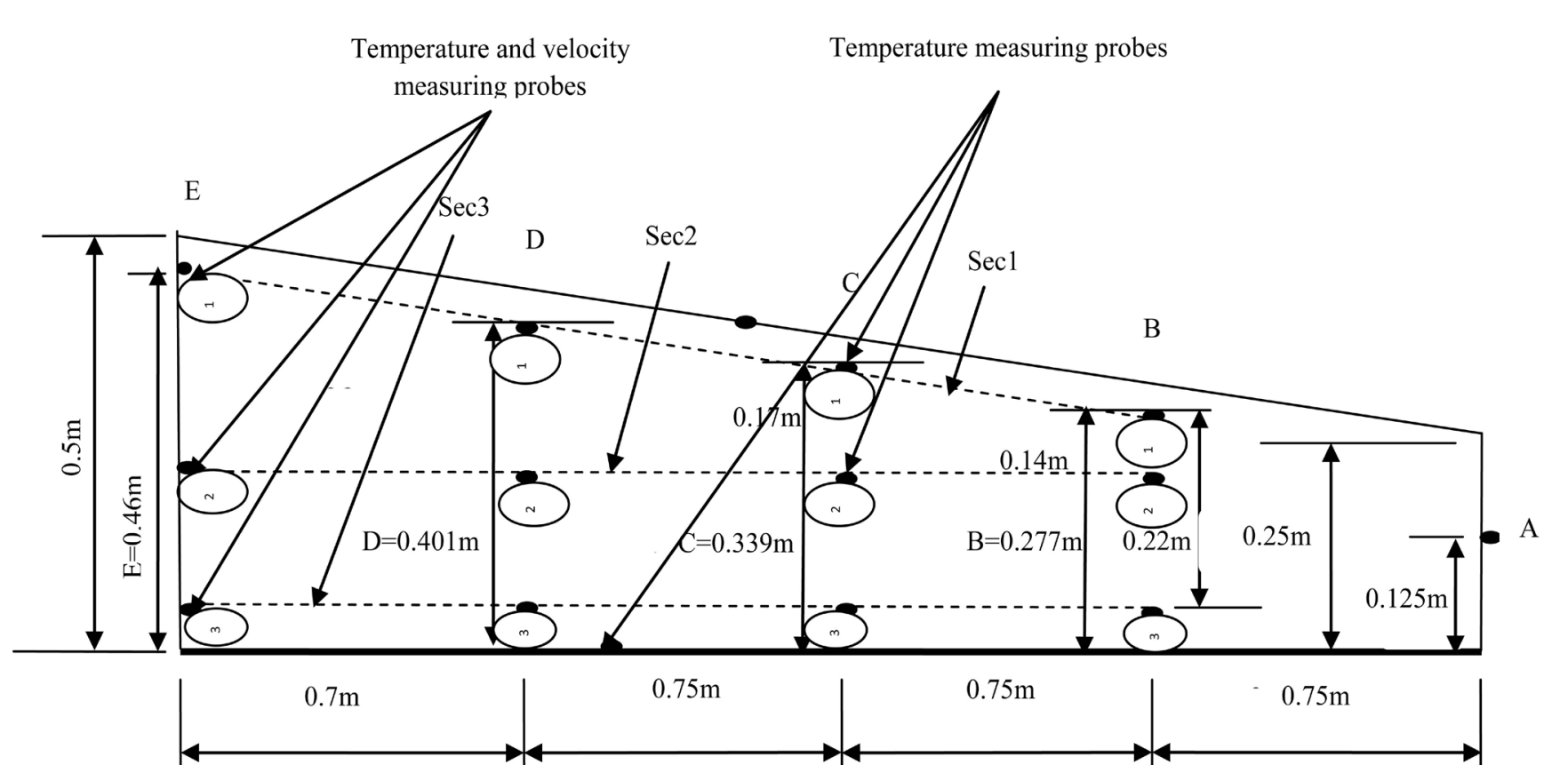

Figure 3. Schematic diagram of a solar collector and measuring points.

uncertainty of $\pm 0.2^{\circ} \mathrm{C}$. The temperature of the solar collector cover and the ground.

The air speed was measured using PASCO PS-2100A USB Link that it has an interface that uses the Universal Serial Bus protocol to enable communication between PASCO sensors and a USB-compatible computer that is running PASCO's data acquisition software which has uncertainty of $\pm 0.1 \mathrm{~m} / \mathrm{s}$. The solar radiation is measured using Protective Glass Dome and Solar Shield (pyranometer) with uncertainty of \pm 0.1 $\mathrm{W} / \mathrm{m}^{2}$.

\section{Thermal Analysis}

To predict the performance of the device under study, this study was developed mathematical model based on previous work [13] [14]. The mathematical model was developed to predicted the temperature of the ground, overall heat transfer coefficients through calculating the temperature of the solar collector cover, the mass flow rate and the of the air at the outlet air temperature from the solar collector $T_{2}$, this section is nearly at the chimney entrance.

The thermal analysis of a solar chimney depends on parameters such as the ambient conditions and structural dimensions of the system. The former includes quantities such as the solar radiation intensity and ambient temperature.

The following analytical expressions are obtained for the mathematical model that it will be predict the solar collector cover, ground temperatures and the amount of heat gained by the land from the solar radiation.

The energy balance equations for the solar radiation incident on the solar collector can be written as follows [13]:

$$
q_{\text {added }}=I\left(\alpha_{\text {ground }} \tau_{\text {glass }}\right)-U_{t}\left(T_{\text {ground }}-T_{\text {amb }}\right)
$$


Which $q_{\text {added }}$ is the heat receipt from the solar radiation and added to the air flow, $\sigma$ is stefen boltez constant, $\varepsilon$ is emittance between sky an ground refers to heat received to the ground, $A_{r}$ is ground area, roof of collector area, $T_{g}$ is the ground temperature and $T_{a}$ is an ambient temperature, $I$ solar radiation $\left(\mathrm{W} / \mathrm{m}^{2}\right), \Delta T$ is the temperature difference between the ground and ambient and $U_{t}$ is the overall heat transfer coefficient.

The following expressions for the first mathematical model are obtained for the temperatures of the solar collector cover through the following steps to calculate the solar collector cover temperature and overall heat transfer coefficient:

Initially the equation of overall heat transfer coefficient can be expressed as follow;

$$
U_{t}=\left(\frac{1}{h_{c, g-c}+h_{r, g-c}}+\frac{1}{h_{w}+h_{r, c-a}}\right)
$$

where, $h_{c, g-c}$ is a convection heat transfer coefficient between the solar collector cover and the ground, $h_{r, g-c}$ is a radiant heat transfer coefficient between the collector cover and the ground, $h_{r, c-a}$ is a radiant heat transfer coefficient between the collector cover and the ambient, $h_{w}$ is the wind coefficient.

Radiation heat transfer coefficients that were mentioned in Equation (2) can be expressed as follows;

$$
h_{r, g-c}=\left(\sigma \frac{\left(T_{g}^{2}+T_{C}^{2}\right)\left(T_{g}-T_{C}\right)}{\frac{1}{\varepsilon_{g}}+\frac{1}{\varepsilon_{C}}-1}\right)
$$

Which $\varepsilon_{g}$ is the emittance between sky and the ground refer to heat received, $\varepsilon_{c}$ is the emittance of the solar collector cover and $T_{C}$ is the collector cover temperature.

$$
h_{r, c-a}=\sigma \varepsilon_{C}\left(T_{C}^{2}+T_{S}^{2}\right)\left(T_{C}+T_{S}\right)
$$

That $T_{S}$ is the temperature of the sky refers to ambient temperature.

After calculations the radiant heat transfer coefficients, the remaining part of the Equation (2) can be expressed as follows;

$$
h_{w}=2.8+3.0 \mathrm{~V}
$$

Which $h_{w}$ is representing the wind coefficient $V$ is the wind velocity.

The convective heat transfer coefficient was the last term in the Equation (2), the following Expression can represent it;

$$
h_{c, g-c}=\frac{N u k}{L}
$$

Which $h_{c, g-c}$ is a convective heat transfer coefficient between ground and the cover of the solar collector, Nusselt number $\mathrm{Nu}$ for natural convection of smooth solar collector is calculated using the following Holland's correlation, Hollands et al [13];

$$
N u=1+1.44\left[1-\frac{1708(\sin 1.8 \beta)^{1.6}}{R a \cos \beta}\right]\left[1-\frac{1708}{R a \cos \beta}\right]^{+}+\left[\left(\frac{R a \cos \beta}{5830}\right)^{1 / 3}-1\right]^{+}
$$


For $0<R a<10^{5}, 0 \leq \theta<60^{\circ}$

Which $\theta$ is the tilt angle of the solar collector that is represents the inclination of the solar collector cover; It has a value of $4.76^{\circ}$ in the current work. Rayleight number; $R a$ is dimensionless number defined as;

$$
R a=\frac{g \beta^{\prime} \Delta T L^{3}}{v \alpha}
$$

where $h$ is heat transfer coefficient, $L$ is the space between the collector cover and the ground, $k$ is represent the thermal conductivity of the air for heat acceptance from the ground, $\mathrm{g}$ is gravitational constant, $\beta^{\prime}$ represents the volumetric coefficient of expansion (for an ideal gas, $\beta^{\prime}=1 / T$ ), $\Delta T$ is the temperature difference between layers of the air along the collector and the ground, $v$ is kinematic viscosity of the air inside the collector, $\alpha$ is thermal diffusivity.

The notations []$^{+}$in the Equation (8) are used to denote that if the quantity in the bracket is negative it should be equal to zero.

Convective heat transfer coefficient $h_{c, g-c}$ could be obtained from solving Equation (7) and Equation (8).

By compensation equations from (3) to (6) within the Equation (2), overall heat transfer coefficient now can be obtained by solving Equation (2).

After substituting the values of $U_{t}$ and the value of the ground temperature can be assumed that can build an initial guess for the solar collector cover temperature and applied for the following expression that calculation of the glass cover temperature $T_{c}$ has been done;

$$
T_{c}=T_{g}-\frac{U_{t}\left(T_{g}-T_{a}\right)}{h_{c, g-c}+h_{r, g-c}}
$$

These results are then used to calculate $\left(T_{c}\right)$ from the Equation (9). If $T_{c}$ is close to the initial guess, no further calculations are necessary, and then get the true value of a total loss $U_{t}$ and the value of heat added to the ground $q_{\text {added }}$ otherwise, the newly calculated $T_{c}$ is used and the process is repeated.

After the heat added to the air inside the solar collector and heat transfer coefficient are calculated, the outlet air temperatures from the solar collector and mass flow rate are calculated using the following set of analytical expression

Under conservation of mass;

$$
\dot{m}=\text { constant }
$$

where;

$$
\dot{m}_{s c}=\dot{m}_{c h}=\rho_{2} A_{c h} V_{c h}
$$

Which $\dot{m}_{s c}$ is the mass flow rate of air in the solar collector, $\dot{m}_{c h}$ is the mass flow rate inside the chimney $V_{c h}$ refers to the velocity at the entrance of the chimney.

The following expression that it will be representing the mass flow rate inside the chimney, it is shown as a function in the temperature of air inlet to the chimney $T_{2}$ and the outlet temperature from the chimney $T_{4}$ that it can be nearly equal to the am- 
bient temperature [15];

$$
V_{c h}=\sqrt{2 g H\left(T_{2}-T_{4}\right) /\left(T_{0}+\left(T_{2}-T_{4}\right)\right)}
$$

By substituting with Equation (12) into Equation (11) then;

$$
\dot{m}_{c h}=\rho_{2} A_{c h} \sqrt{2 g H\left(T_{2}-T_{4}\right) /\left(T_{0}+\left(T_{2}-T_{4}\right)\right)}
$$

For simplicity, frictional effect has been ignored since the velocity in this region is quite low. Because the flow is in the very low Mach number regime, the kinetic energy contribution can be safely neglected, therefore:

$$
q_{\text {added }} A_{r}=\dot{m} C_{P}\left(T_{2}-T_{1}\right)
$$

where, $q_{\text {added }}$ is heat added to the solar collector from the ground by natural convection heat transfer, $A_{r}$ is the area of the solar collector, $\Delta T$ represents the temperature difference of the air flow from the inlet and outlet from the solar collector. Assuming that $q_{\text {added }}, C_{P}$ and $\dot{m}$ are constant, $\rho$ and $T$ can be approximated to be $\rho_{1}$ and $T_{1}$ without significantly affecting the numerical values of the terms.

The Mach number $\left(M=\sqrt{\gamma R T_{2} / V_{c h}}\right.$ ) is again assumed to be very low and thus can be neglected; the Equation (14) is then simplified to be:

$$
p_{2}=p_{1}+\frac{\dot{m} q_{\text {added }}}{2 \pi h_{\text {coll }}^{2} \rho_{1} C_{p} T_{1}} \operatorname{In} \frac{r_{\text {coll }}}{r_{c h}}-\frac{\dot{m}^{2}}{2 \rho_{1}}\left(\frac{1}{A_{c h}^{2}}-\frac{1}{A_{c, \text { flow }}^{2}}\right)
$$

Which; $h_{\text {coll }}$ is the height of collector roof from the ground. $r_{\text {coll }}$ is a radius of the solar collector and $r_{c h}$ is the chimney radius.

From Equation (14), the following analytical expression can be obtained for the outlet temperature of the air from the solar collector:

$$
T_{2}=T_{1}+\frac{q_{a d d e d} A_{r}}{\dot{m} C_{P}}
$$

If the work extraction process at the turbine is assumed to be an isentropic process, then;

$$
T_{3}=T_{2}\left(\frac{p_{3}}{p_{2}}\right)^{\frac{\gamma-1}{\gamma}}
$$

Furthermore, by rearranging the momentum and continuity equations for the flow through a constant area vertical tower of height, $h_{\mathcal{c}}$ and the following analytical expression can be obtained;

$$
p_{3}=p_{4}+0.5\left(\rho_{3}+\rho_{4}\right) \cdot g \cdot l_{c h}+\left(\frac{\dot{m}}{A_{c}}\right)^{2}\left(\frac{1}{\rho_{4}}-\frac{1}{\rho_{3}}\right)
$$

If we consider the air is atmospheric air outside the solar chimney system, the hydrostatic equilibrium requires that;

$$
\frac{\mathrm{d} p}{\mathrm{~d} z}=-\rho g
$$

According to Ref. Calvert et al [16], when the atmospheric air is regarded as an un- 
saturated medium and expands slowly to a lower atmospheric pressure without exchange of heat, the dry adiabatic. The temperature lapse rate equation can be obtained and written as;

$$
T=T_{\infty}-\frac{g}{C_{p}} z
$$

Assuming that the air obeys the ideal gas equation of state, Equation (20) can be substituted into Eq. (19) to give the value of the air flow pressure $p_{4}$ at the outlet section for the chimney outside air as;

$$
p_{4}=p_{3}\left(1-\frac{g}{T_{3} C_{p}} h_{c h}\right)^{\frac{C_{p}}{R}}
$$

In accordance with Equation (20) and consider that a dry adiabatic lapse rate can be applied to the flow in a chimney, the following expression can be obtained for the air temperature at the outlet section a of the chimney.

$$
T_{4}=T_{3}-\frac{g}{C_{p}} h_{c h}
$$

For an ideal gas, according to [14] the expression of the air density at specified point can represented as follows;

$$
\rho_{2}=\frac{p_{2}}{R T_{2}}, \rho_{3}=\frac{p_{3}}{R T_{3}}, \rho_{4}=\frac{p_{4}}{R T_{4}}
$$

Figure 4 shows that the solution procedures were performed according to first and second mathematical models that it was modified from [13] [14], the mass flow rate is known as a function of $T_{2}$ then The steps of calculating the outlet temperatures from the solar collector are proceeding.

\section{The Solar Collector Efficiency}

The efficiency of the flat plate solar collector is the ratio of the useful energy from radiation incident from the sun represented by $\left(q_{\text {added }} \cdot A_{r}\right)$ To the useful energy out from the collector that is obtainedfromthe air while flowing inside the solar collector and represented by $\left[\dot{m} C_{p}\left(T_{2}-T_{1}\right)\right][14]$;

$$
\eta_{c}=\frac{\dot{m} C_{p}\left(T_{2}-T_{1}\right)}{q_{\text {added }} \cdot A_{r}} .
$$

where $T_{1}$ is the inlet air temperature of the solar collector, $T_{2}$ is the outlet air temperature of the solar collector, $C_{p}$ is the specific heat of air at constant pressure and $q_{\text {added }}$ is heat added from the solar radiation fall on the ground across the cover of the solar collector, $A_{r}$ is the area of the solar collector.

The iteration for the above loop begin by Guess $p_{3}$, and then calculate $T_{3}, \rho_{3}, T_{4}, \rho_{4}$ using Equations ((17), (23), (22)) and Equation (23), respectively. Calculate $p_{3}$ using Equation (18), and then compare the new $p_{3}$ to the former $p_{3}$. Perform the iteration and Calculation $\dot{\mathrm{m}}$ using Equation (13). 


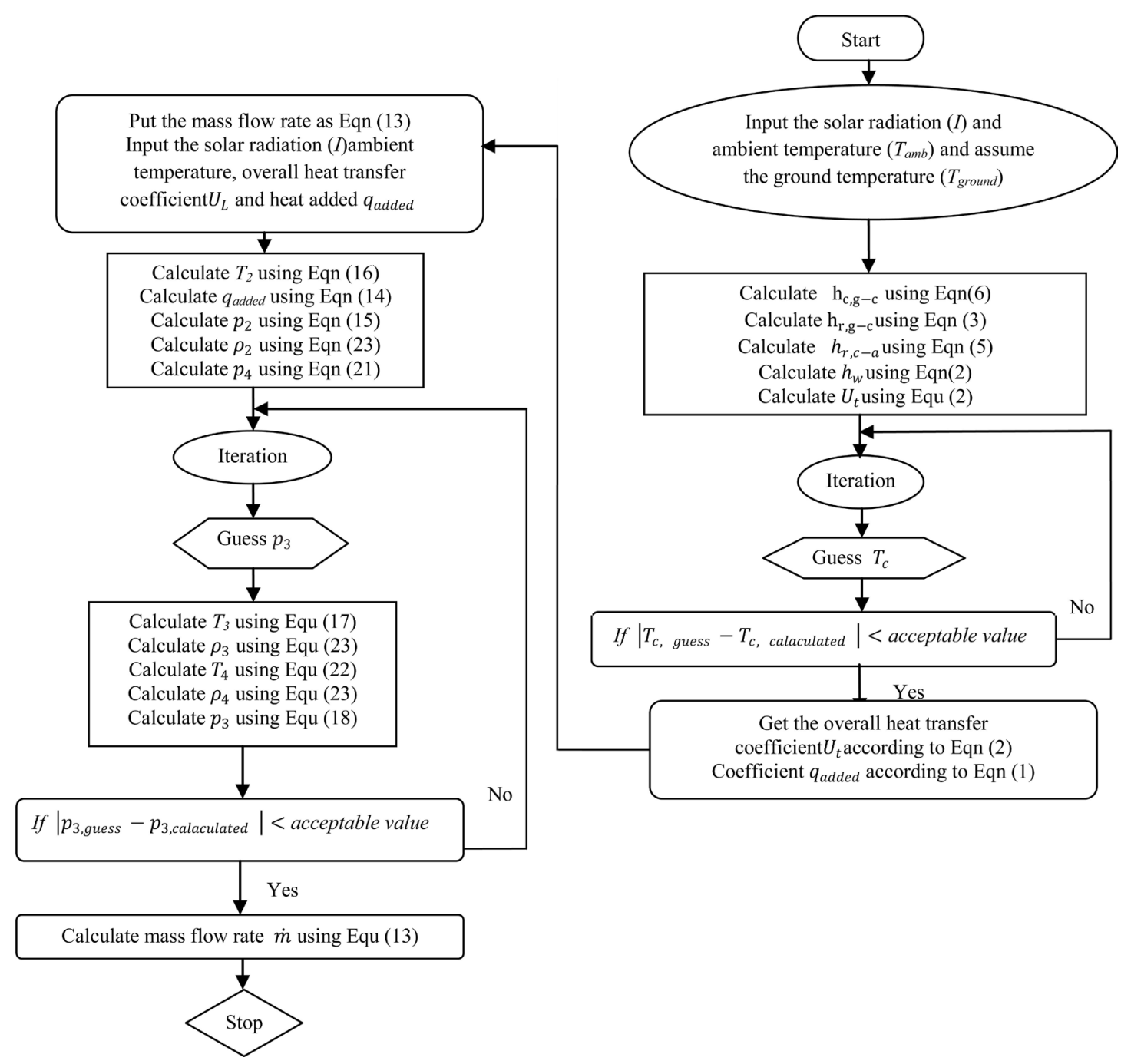

Figure 4. Flowchart of solution procedures.

\section{Computational Model}

In this part of the study, the numerical simulation of the solar collector is presented. A physical model for a solar collector was built based on the geometrical dimensions of the experimental test rig. The numerical study has used a commercial code CFX, ANSYS 16.1 to simulate the flow through the solar collector, computations using a radiation model that it was solved the heat transfer through the solar collector, radiation heat transfer mainly occurs in the collector, which is covered by a semi-transparent material (plastic cover). The cover material is nearly transparent for incident solar radiation, but partly opaque to infrared radiation from the ground. In the present simulations, the discrete radiation model model was adopted to solve the radiated transfer equation, Numerical results are used for comparison with the theoretical predictions. . Heat transfer in the solar collector involves three modes: conduction, convection, and radiation. In simulating the flow in the solar collector, computations using models that only focus on conduction and convection are the simplest, whereas those involving 
driven force of the flow and radiation model are more complex.

Discrete radiation model was used to solve the radiative transfer equation for the following reasons:

Only this model can be used to solve the solar collector using semi-transparent walls of various types, it can be used to compute non-gray radiation using a gray band model and it can work well across a full range of optical thicknesses.

The Boussinesq model was inserted in this simulation. This model treats density as a constant value in all solved equations for the solar collector.

$$
\left(\rho-\rho_{a}\right) g \approx-\rho_{a} \beta\left(T-T_{a}\right) g
$$

where $\rho_{a}$ the density of ambient air, $T_{a}$ is the ambient temperature, and $\beta$ is the thermal expansion coefficient. For the buoyancy driven flow, faster convergence can be achieved by using the Boussinesq model than by setting air density as a function of temperature.

The model simulation was depends on the boundary condition that it was collected from the theoretical model, the boundary conditions and the geometries of the model are tabulated in Table 1.

All numerical calculations had to be carried out with the solver with double precision. The iteration error was at least $10^{-6}$ on all calculations, for the energy equation at least $10^{-9}$. Under these conditions, the solution converged in less than 6000 iterations but this simulation was completely converged in 8000 iterations. The thermal properties of the solar collector components [17] [18] were represent in Table 1.

The main boundary conditions are shown in Table 1 for mass, momentum and energy conservation equations, and the temperature profiles of the ground and the collector cover in the collector could be different parabolic functions of the collector ra-

Table 1. Design and operated condition of the system.

\begin{tabular}{cc}
\hline Description & Values \\
\hline Collector radius $\left(r_{c}\right)$ & $3 \mathrm{~m}$ \\
chimney high $\left(h_{c h}\right)$ & $6 \mathrm{~m}$ \\
chimney radius $\left(r_{c h}\right)$ & $0.075 \mathrm{~m}$ \\
Plastictransmissivity, visible light range. $\left(\tau_{g}\right)$ & 0.86 \\
Plastic conductivity $\left(k_{c}\right)$ & $0.2 \mathrm{~W} / \mathrm{m} \cdot \mathrm{K}$ \\
Plastic thickness $\left(h_{c}\right)$ & $0.0015 \mathrm{~m}$ \\
Ground emissivity $\left(e_{\text {surf }}\right)$ & 0.9 \\
Ground conductivity $\left(k_{g}\right)$ & $0.6 \mathrm{~W} / \mathrm{m} \cdot \mathrm{K}$ \\
Ground heat transfer coefficient $\left(h_{g}\right)$ & $2.4 \mathrm{~kJ} / \mathrm{kg} \cdot \mathrm{K}$ \\
Collector inlet temperature at $(2: 00 \mathrm{pm})$ & $38^{\circ} \mathrm{C}$ \\
Collector inlet pressure & $98.3 \mathrm{kPa}$ \\
Thermal storage depth & $0.04 \mathrm{~m}$ \\
Wind speed at collector inlet & $1.2 \mathrm{~m} / \mathrm{s}$ \\
\hline
\end{tabular}


dius by taking into account the axisymmetric air flow in the collector shown in the second assumption above, and the functions will vary with different solar radiations.

\section{Grid Independence Test}

An investigation of grid independence was carried out to find the proper mesh. The test was performed on the velocity along the chimney. Four different grids were checked (705,521 elements, 1,253,241 elements, 1,596,164 elements, and 1,850,644 elements). There are relatively small (typically less than 5 percent) differences between the respective grid no. 3 (1,596,164 elements) and grid no. 4 (1,850,644 elements) results for the most stringent quantities of the velocity along the chimney. This indicates that both of the two grids are approaching grid independence as shown in Figure 5. All results in the following discussions are done for grid no. 3 case to reduce the time of the solution than case no. 4 .

\section{Results and Discussions}

The aim of this section is to present the experimental results obtained in the present research for the performance of the solar collector. A series of test runs are carried out in ten days of May and June 2015 with different ambient conditions to test the performance of the solar collector in terms of the outlet air temperatures from the solar collector, the velocity of the air at the chimney entrance and heat added to the solar collector, Moreover, comparisons between experimental work, theoretical and Numerical results are carried out.

Figure 6 shows hourly variations of the measured solar radiation $(I)$ with time of day for all run days, it is shown from the Figure 7 that the trend of solar radiations in all run days are nearly similar with small differences. On the other hand the maximum value of the solar radiation was reached at 12:00 PM in all run days.

Figures 8-10 are shown that air temperature $T_{a}$ inside the solar collector increases from the beginning of the solar collector to the outlet section of the solar collector, where $T_{a}$ is investigated for all run days at various values of solar radiation. It is noticed that air temperature; $T_{a}$ increases significantly from the outer rim of the collector until

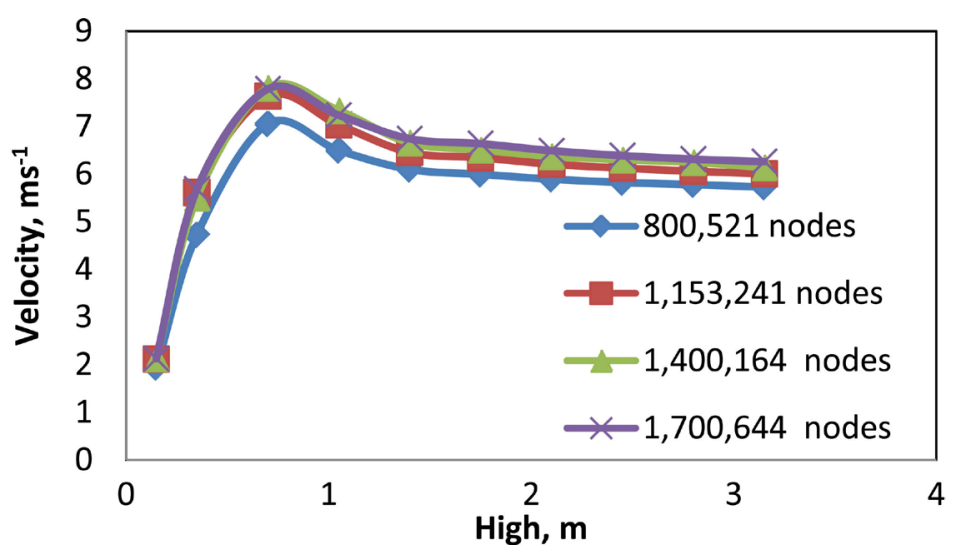

Figure 5. Grid independence check. 


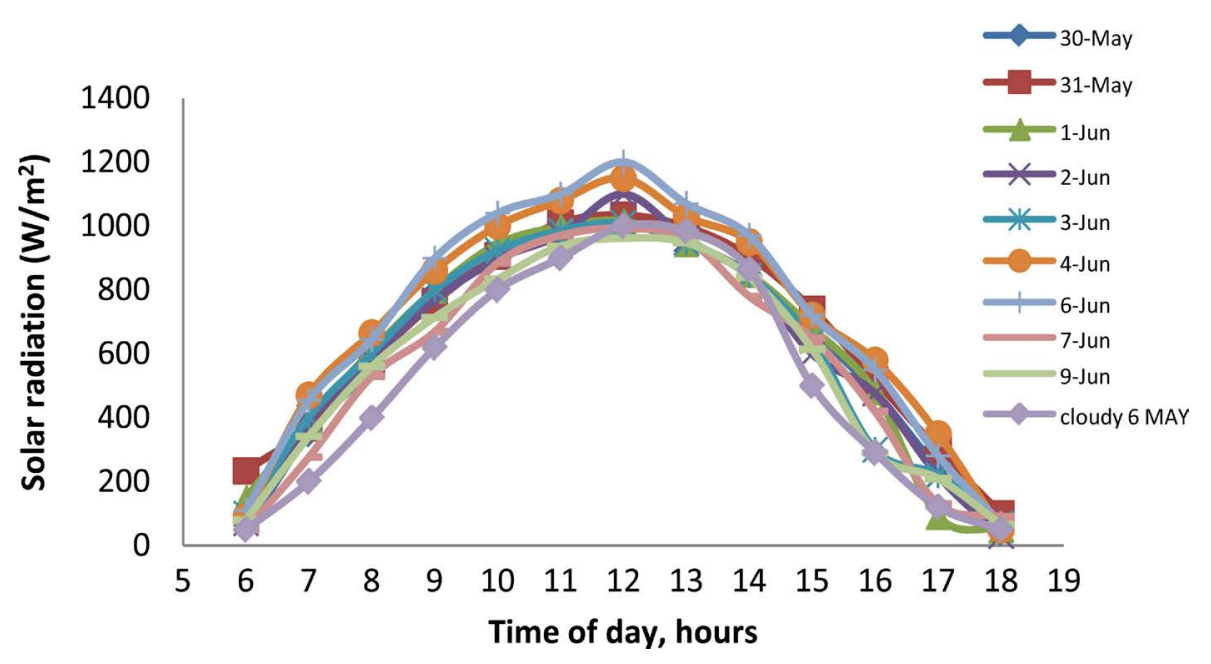

Figure 6. Hourly variation of solar radiation due to all run days.

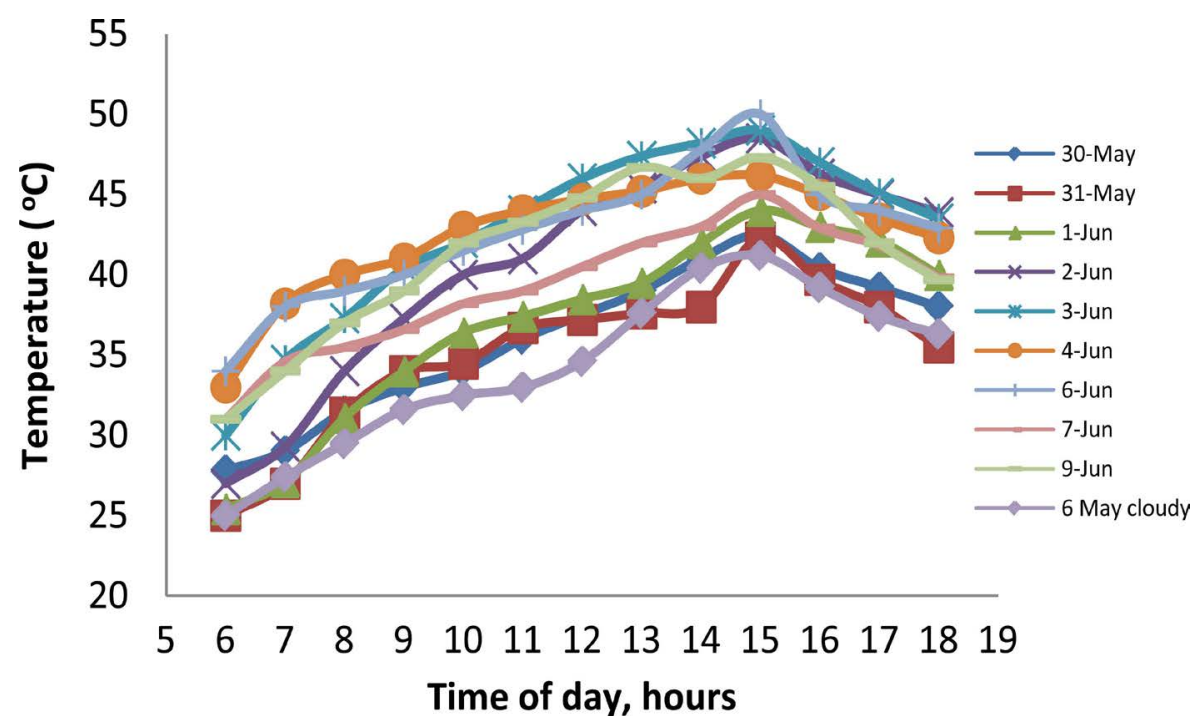

Figure 7. Hourly variation of ambient air temperature in all run days.

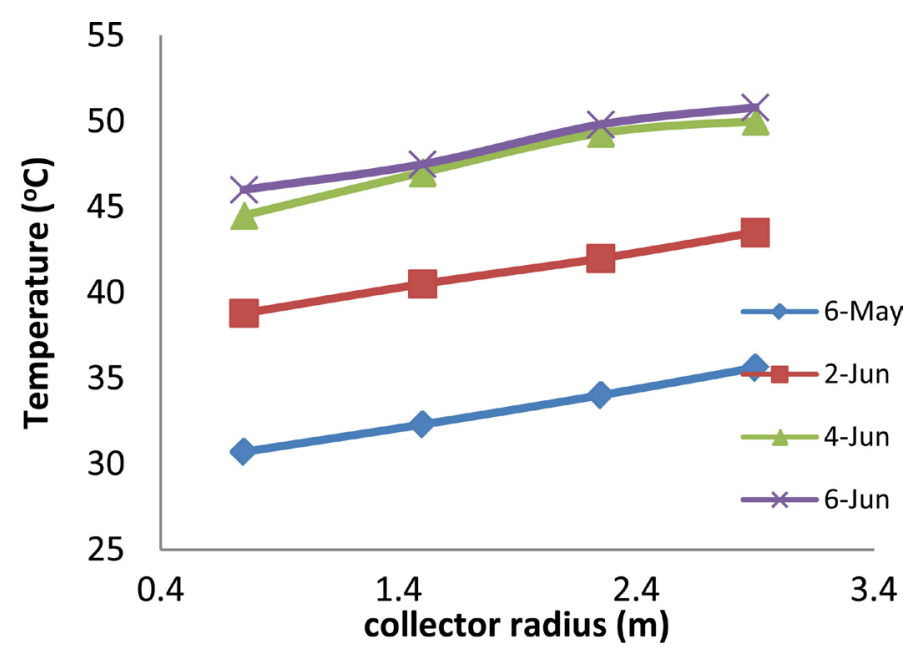

Figure 8. Hourly variation of air temperature; $T_{a}$, versus collector radius at 8:00 AM, for Sec 2 . 


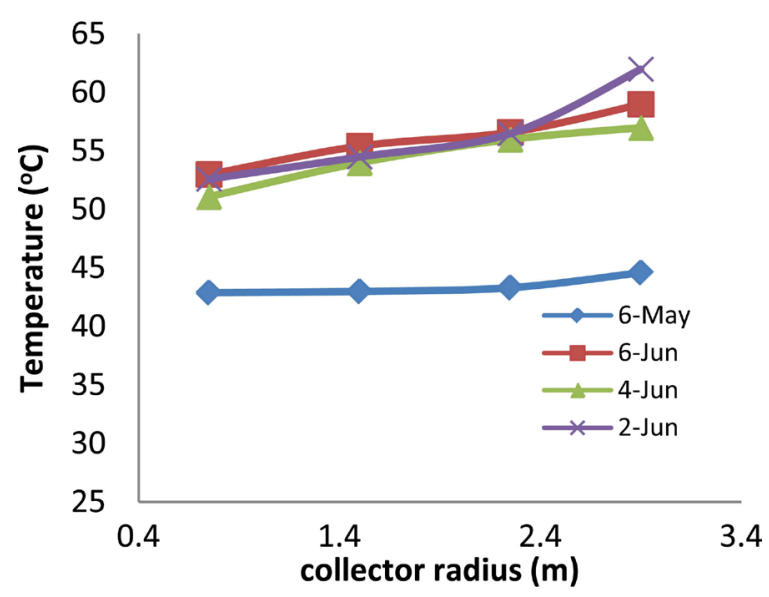

Figure 9. Hourly variation of air temperature; $T_{a}$, versus collector radius at 2:00 PM, for Sec 2 .

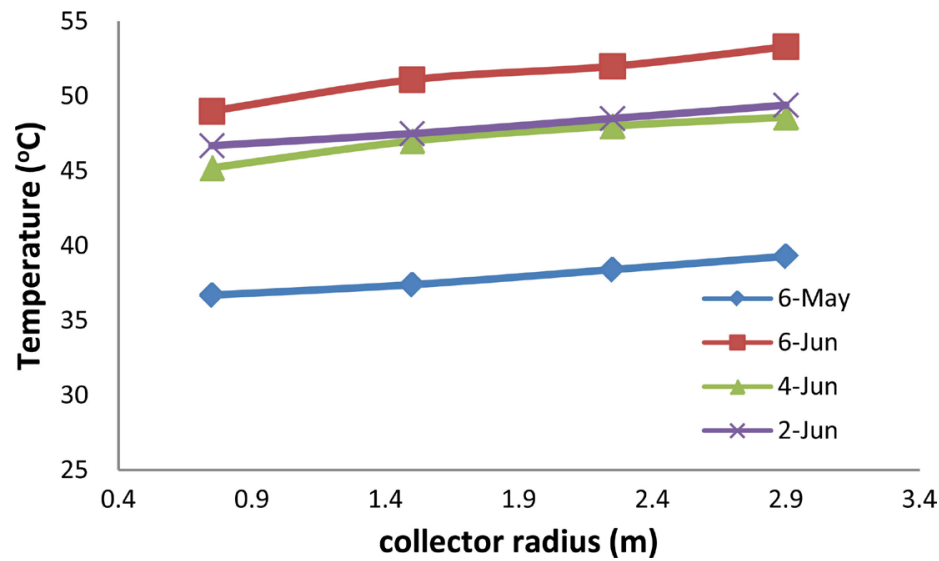

Figure 10. Hourly variation of air temperature; $T_{a}$, versus collector sections at 6:00 pm, for Sec 2 .

it reaches at collector radius at $0.75 \mathrm{~m}$, still increasing but by the small difference until at collector radius $0.05 \mathrm{~m}$. The temperature at this location of the solar collector represents the outlet air temperature of the solar collector the values of $T_{a}$, the observations shows that the maximum temperatures are obtained in the interval from 12:00 PM to 3:00 PM. Peak values will be around 3:00 PM. Practically at the beginning of the sunrise, the air temperature inside the solar collector is nearly close to the ambient temperature. After sunrise, the ground absorbs and stores the radiant energy and of course its temperature is low at the beginning. So, because of low temperature and heat transfer via the solar collector, when the sunrise increases the temperature under the collector warms up, due to the air displacement. The solar warmth is first absorbed by the ground and then the air moving on the surface, absorbs the heat and carries to the upper layers in the direction of the collector cover. Therefore, the temperature decreases from the ground and to the collector cover. The air temperature has the maximum reading near the center of the solar collector and the lowest temperature is related to ambient temperatures at the inlet of the solar collector. The maximum temperature difference between inlet and outlet of the solar collector was recorded at (2:00 PM. On $6^{\text {th }}$ of June, 2015), it was reached $24.5^{\circ} \mathrm{C}$. 
On the other hand; it is noticed that the main reason that the air temperatures $T_{a}$ are increasing inside the collector is the heat accepted from the ground, Figure 11 shows the ground temperature $T_{g}$ for all run days. It is observed that the ground temperatures would be depending strongly on the solar radiation, the maximum temperature of the ground was recorded at 3:00 PM in all run days.

The collector cover temperature is affected by the solar radiation from the sun as shown by Figure 12, but it was less than the ground temperatures, this is according to the specification of the material used in the collector cover and the ground, also the climate conditions that it would because the temperatures of the collector cover nearly close to the ambient temperatures.

Further, it may be observed from the Figures 13-16 that the average outlet air temperature is strongly affected by heat added to the solar collector through the ground that would be added by solar radiation. It may be observed from Figure 13, that across

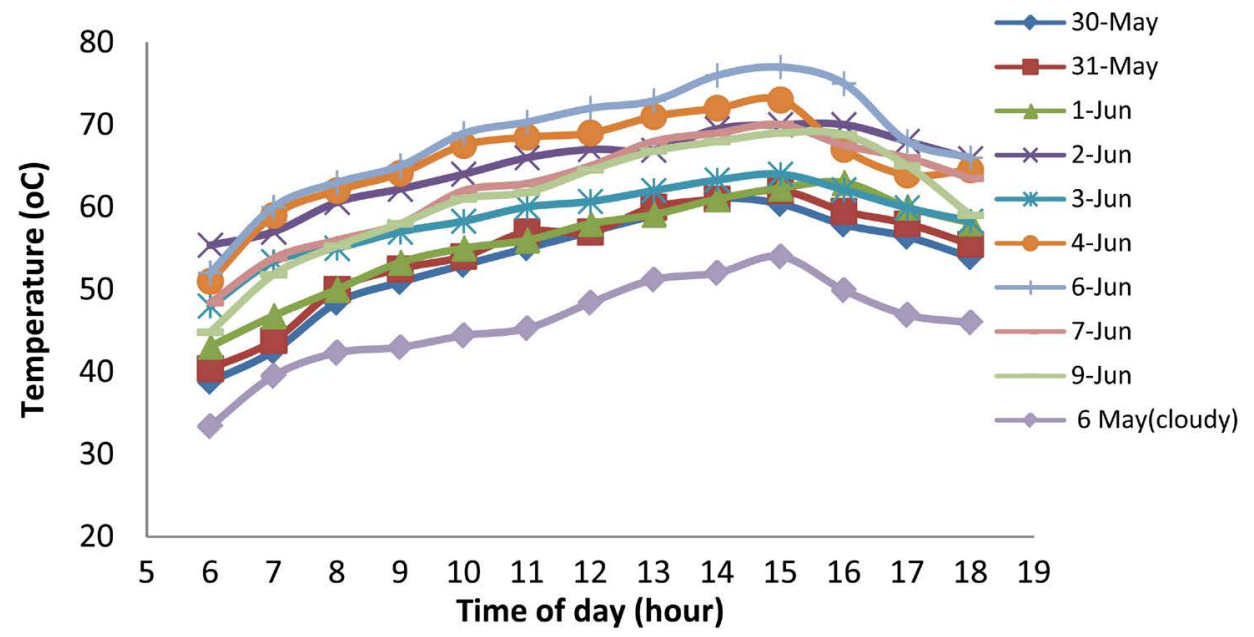

Figure 11. Hourly variation of ground temperature; $T_{g}$, versus time of day for all run days.

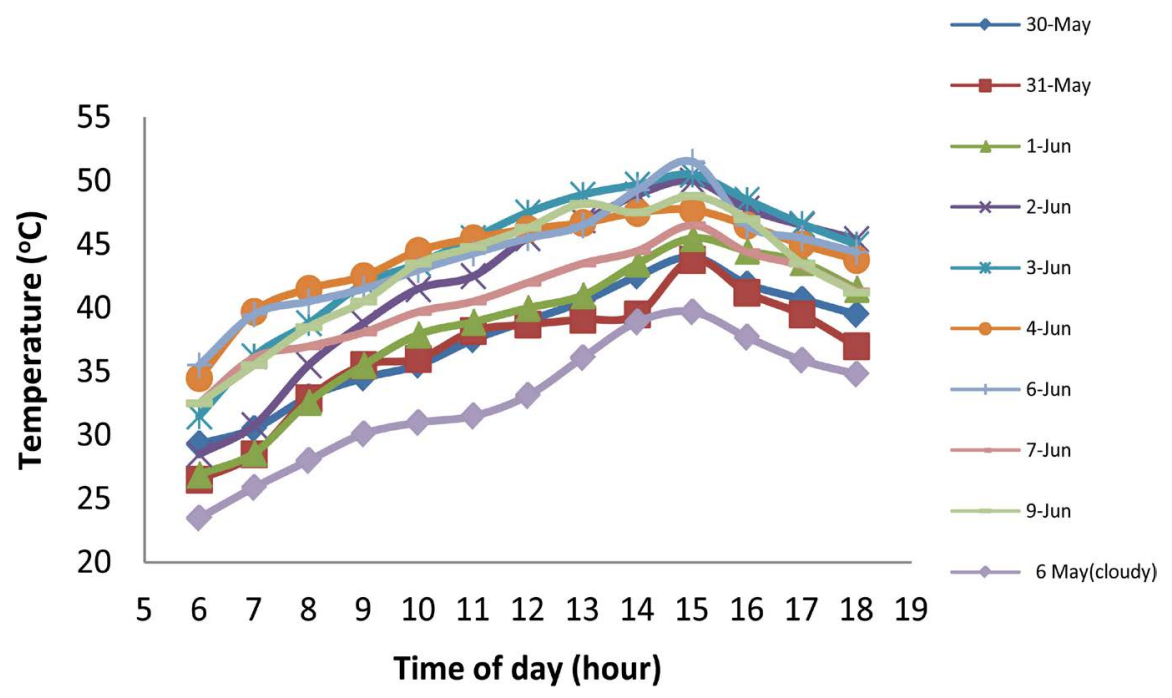

Figure 12. Hourly variation of the collector cover temperature; $T_{\mathcal{C}}$ versus time of day for all run days. 


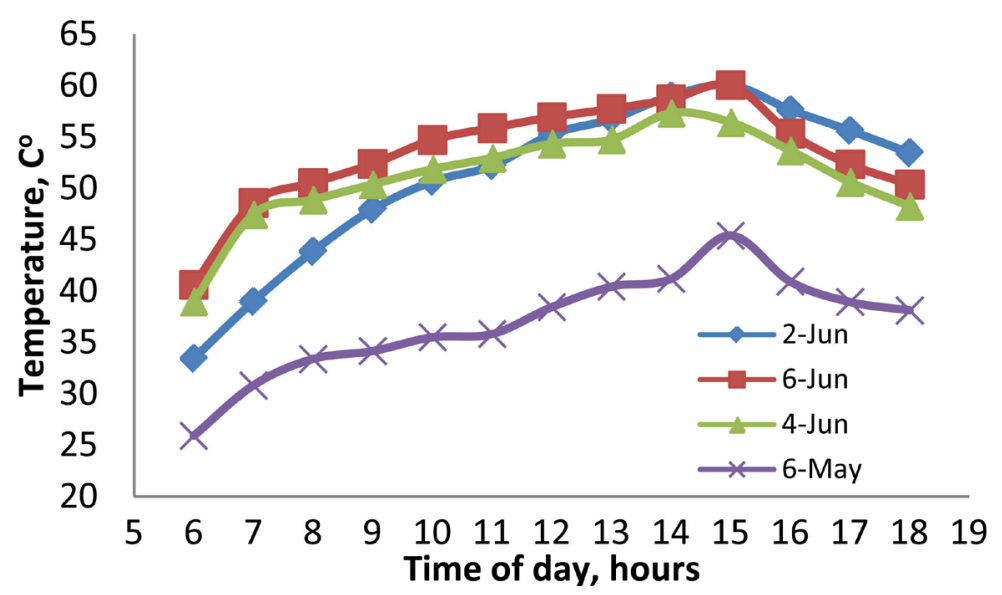

Figure 13. The average Outlet air temperatures $\left(T_{a o}\right)$ from solar collector measured with time of days.

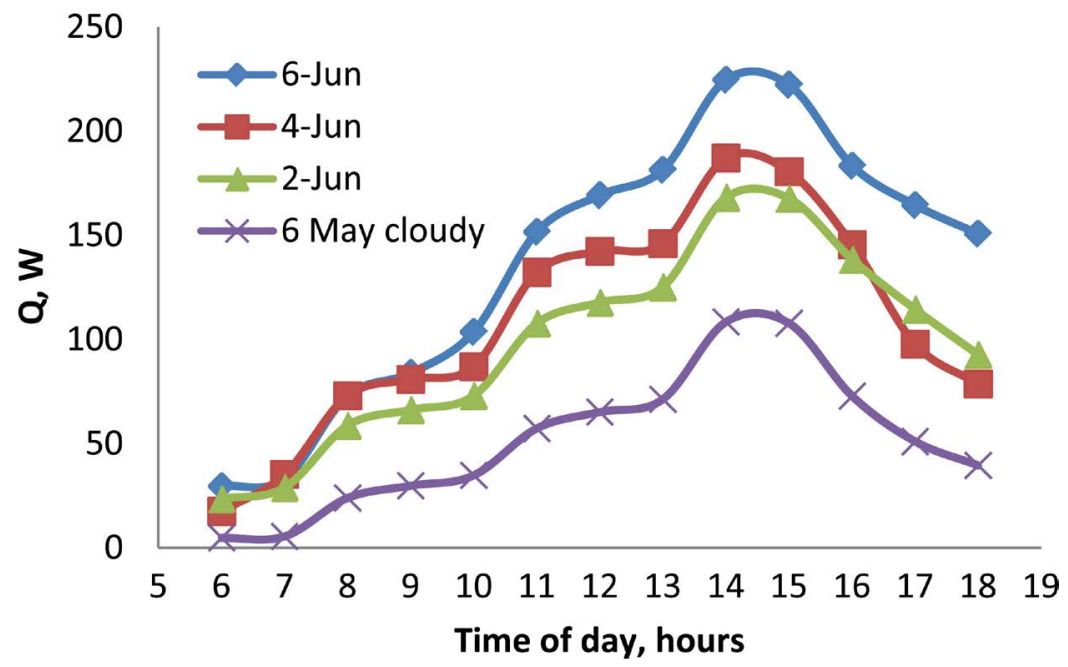

Figure 14. Variation of heat added to the air inside the solar collector $(q)$ with time of days.

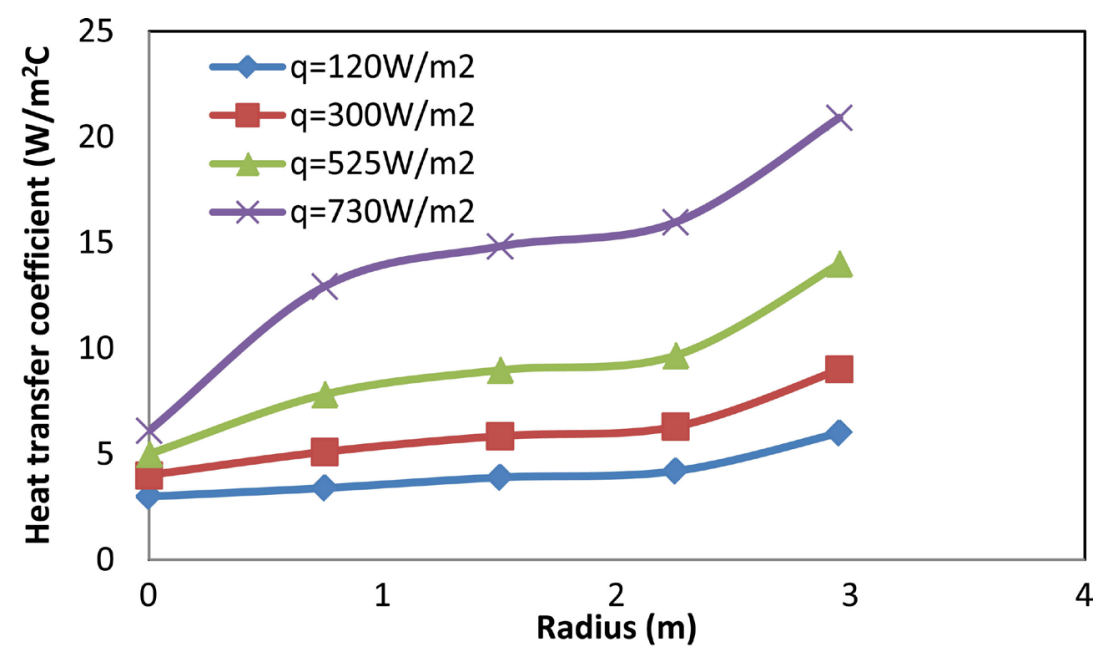

Figure 15. Variation of heat transfer coefficient $\left(h_{c, g-a}\right)$ inside the collector versus collector radius. 


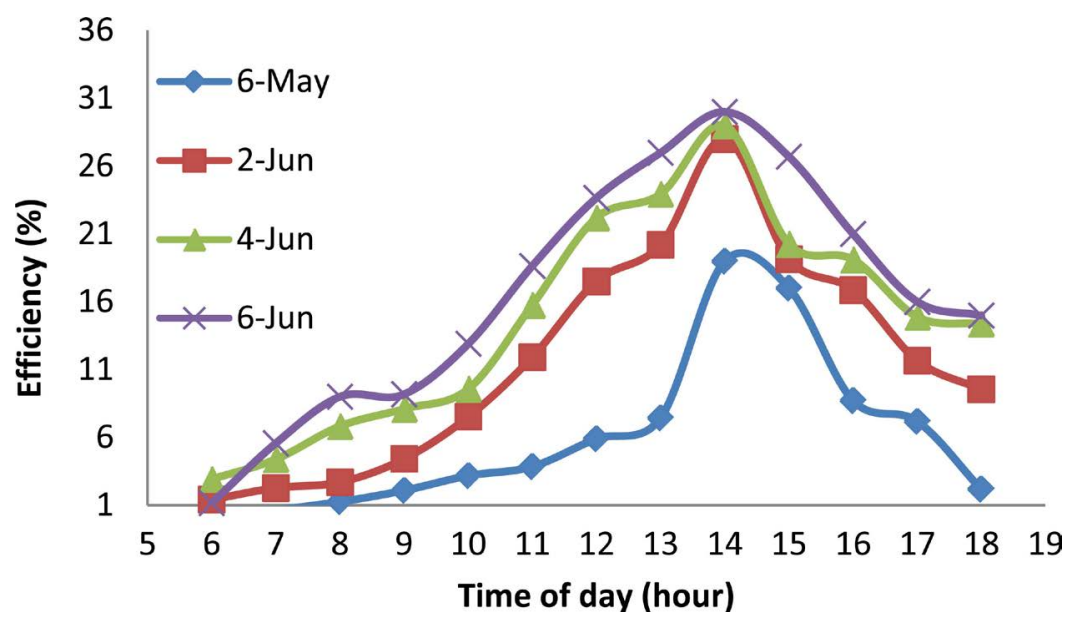

Figure 16. Experimental efficiency of the solar collector.

a day the outlet average temperature of the flowing air through the solar collector increases with increasing solar radiation through a day. The reason for this observations that the increasing in solar radiation at sunrise would be caused increases in heat added to the ground that The ground surface warms and reject the heat to the air layers over the ground that is heated by natural convection due to heat transfer from the ground that will cause rising in air temperature layers from the ground to the collector cover, this observation are shown from Figure 15, it shows the heat transfer coefficient $h_{c, g-a}$ with collector radius. With further increase of solar radiations across a day would be affected on the outlet average temperature of the flowing air for run days by small difference. In addition, this mean that the increasing of the outlet temperatures for air not affected, only by solar radiations and climate conditions, may be another factor cause enhancing in outlet temperatures from the solar collectors such as dimensions and inclination of the collector cover of the collector, painting the ground by black material and placed storage material on the ground such as concrete that have thermal specifications was proportional for the collector for this purpose. Whatever Figure 16 illustrates that the solar collector efficiency increases with increasing the solar radiations across the day.

It may be concluded from the above figures that for solar chimney power plant in the present study, the maximum efficiency range of the solar collector has the dimension stated is recommended to be in range $22 \%$ to $28 \%$ at $60.03^{\circ} \mathrm{C}$ outlet temperature and heat added $270 \mathrm{~W} / \mathrm{m}^{2}$.

Figure 17 shows the numerical result of the temperature distribution of the solar chimney power plant, it can be observed that the temperature over a large area near the center of the solar collector is higher than that at the inlet of the solar collector, it reaches about $61^{\circ} \mathrm{C}$. This is due to the effect of the high heat transfer from the land to the air flow under the collector cover. This will cause the air flow strongly accelerated from the end of the solar collector to the chimney under the buoyancy effects.

Figure 18 shows the effect the average outlet temperature of the solar collector on the velocity at the chimney entrance. The observation shows that the velocity of the 

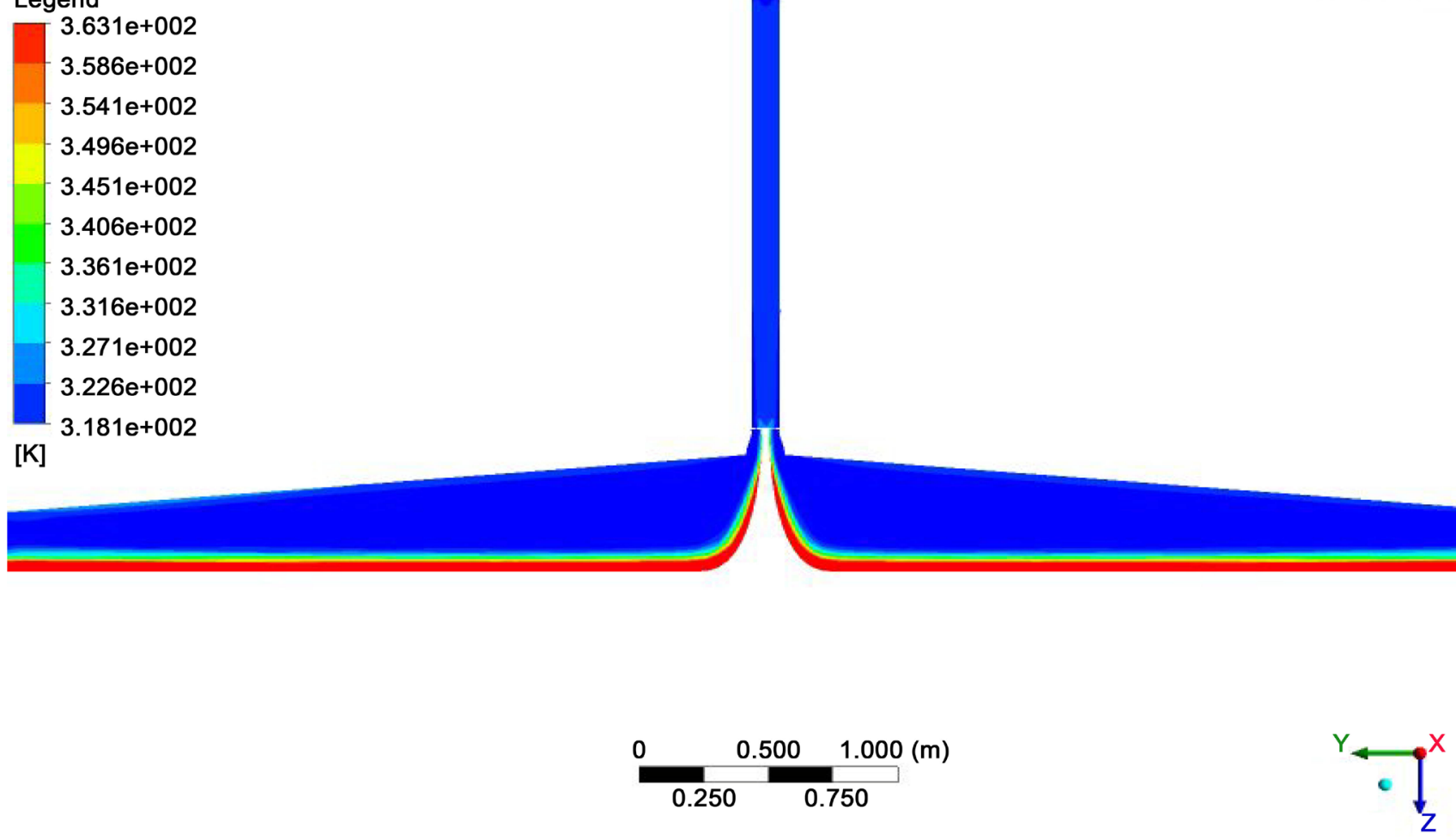

Figure 17. Temperature contours for the solar chimney power plant.

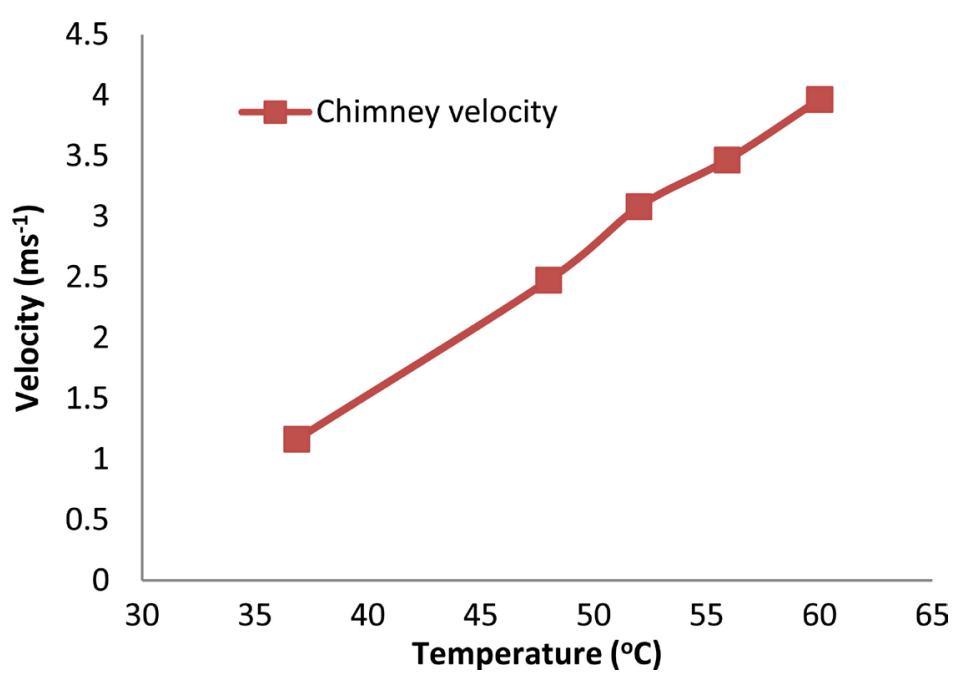

Figure 18. The effect of the air temperatures on chimney velocity.

chimney base increase significantly with the increase in the average outlet temperature of the solar collector, The reason is when all the other parameters such as the environment parameters and the solar radiation are constant, large amount of heat added to the flow in the solar collector increase the energy of the flow, that it was dissipated a part of this energy on the shape of kinetic energy at the chimney entrance. The maximum velocity recorded at $60.3^{\circ} \mathrm{C}$ with a value of $4.2 \mathrm{~m} / \mathrm{s}$. 


\section{Comparison between Experimental Results, Numerical Results and Theoretical Prediction}

Figure 19 and Figure 20 compare the experimental, numerical and the mathematical model results for the predicted outlet air temperature of the solar collector and its efficiency respectively on $6^{\text {th }}$ June from 6:00 AM to 6:00 PM.

The observations show a little higher value in the simulation result than the outlet temperatures from the solar collector than the experimental result by $5.8 \%$, the mathematical model result is higher than the experimental result by $3.03 \%$, on the other hand; for the solar collector efficiency, Figure 20 show that the simulation and mathematical model results for the solar collector efficiency are higher than experimental by $6.5 \%$ and $4.4 \%$ respectively.

Figure 21 is showing a good agreement between experimental, numerical and the mathematical model results for the heat added to the air in the solar collector the observations are showing that the simulation and mathematical model results for the solar collector efficiency are higher than experimental by $8 \%$ and $4.3 \%$ respectively.

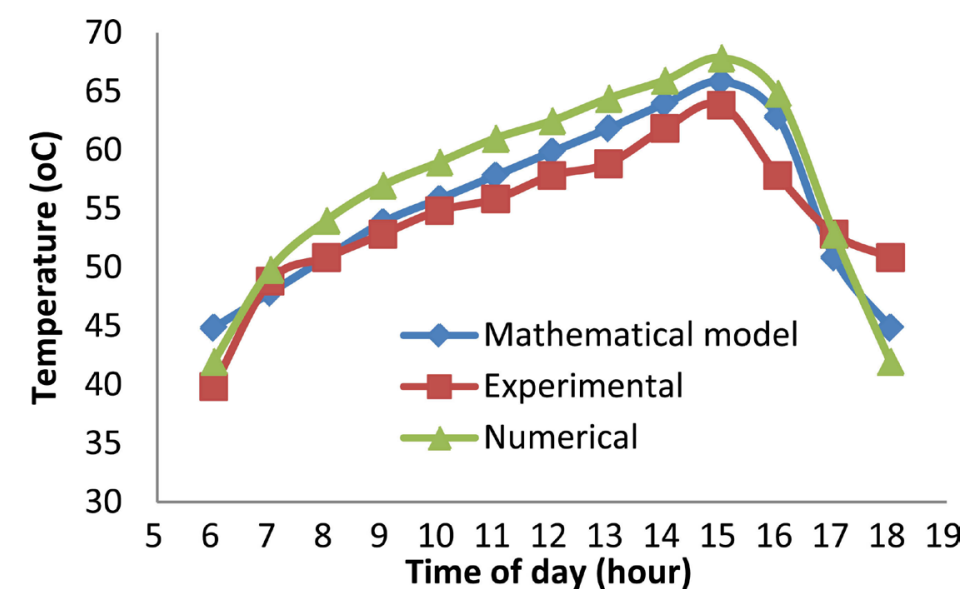

Figure 19. Experimental, mathematical model and numerical results for the outlet air temperature of the solar collector.

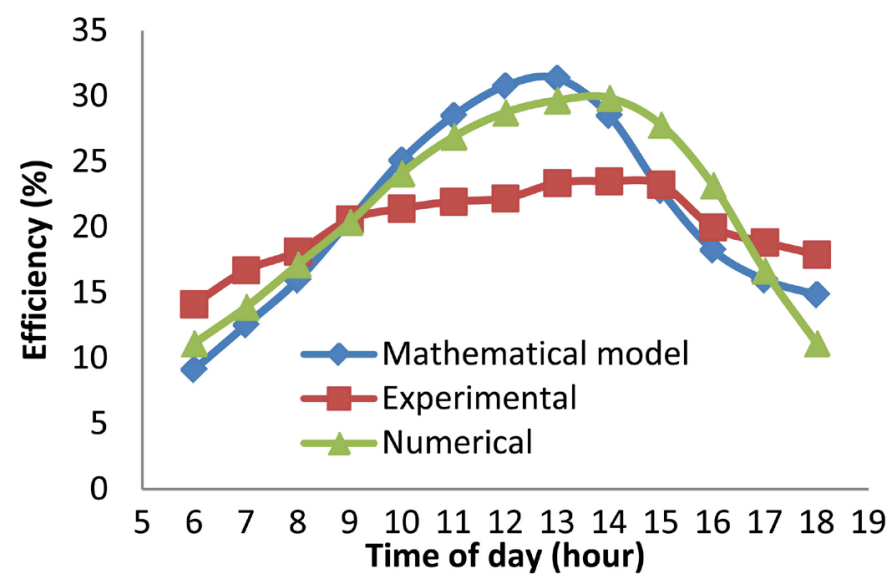

Figure 20. Experimental, mathematical model and numerical result of the solar collector efficiency. 


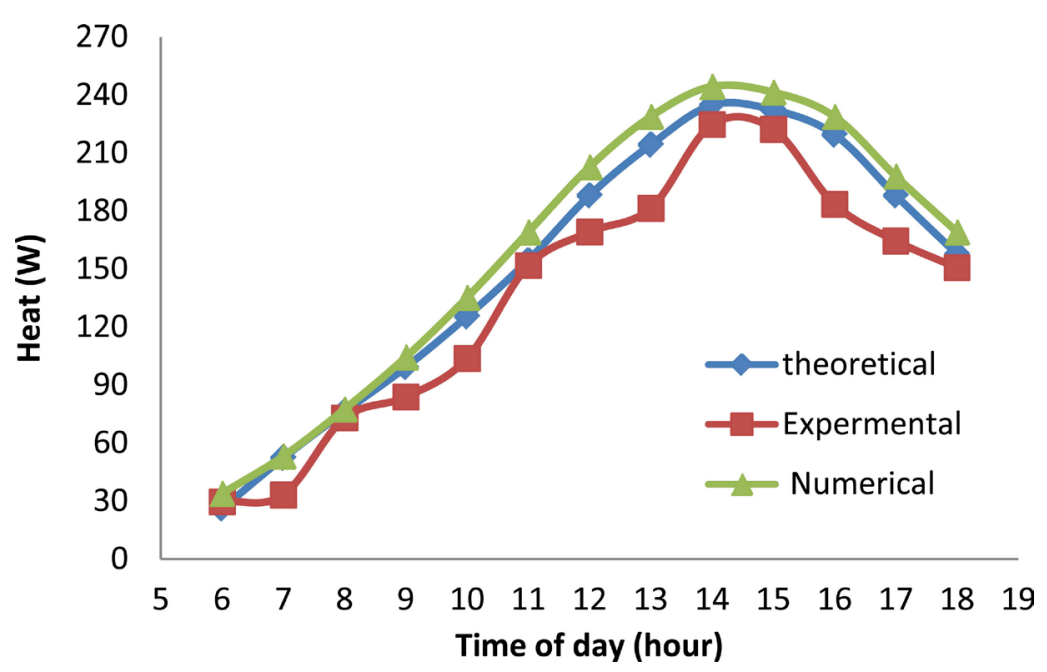

Figure 21. Experimental, mathematical model and numerical result for the heat added to the air inside the solar collector

\section{Conclusions}

On the basis of the experimental, numerical and theoretical results obtained for ten run days for the solar collector manufactured and tested in Aswan, Egypt, the following conclusions can be drawn:

1) The existence of Aswan near the pass of Tropic of Cancer is a major reason for the high solar radiation values that it has been recorded a high value about $1200 \mathrm{~W} / \mathrm{m}^{2}$.

2) Air, ground and the collector cover temperatures in general increase along the solar collector.

3) Solar radiation, climate condition and clarity of the sky are predominant factors which affect the performance of the solar collector. Increasing the solar radiations with clarity of the sky was caused a consequent increase of air, ground and the collector cover temperatures.

4) Despite of the smaller scale of the solar chimney power plant but the difference between the outlet air temperatures from the solar collector above the ambient air temperature was reached $24.5^{\circ} \mathrm{C}$; this is specified as the highest performance because the climate of the location that the system is built.

5) The maximum outlet temperature of the solar collector is $60.3^{\circ} \mathrm{C}$ that it is produce maximum velocity at the chimney inlet with $5.5 \mathrm{~m} / \mathrm{s}$.

6) In sunshine period, heat added to the solar collector would increase until maximum values reached afternoon at 2:00 PM and decrease until the 6:00 PM period.

7) The heat transfer coefficient in the solar collector that represent by heat added to the air in the solar collector was affected by solar intensity and clarity of the sky.

8) This study produced a modified a mathematical model that it was based on previous research

9) It is concluded that the mathematical model is basically valid for the solar collector system, and the simulation with the model can be used conveniently to predict the performance of the system, the comparison between them and experimental result 
shows a good agreement.

10) Aswan is the good site to solar chimney power plant generation technology according to the clarity of the sky and the warming of the climate.

\section{References}

[1] Lorente, S., Koonsrisuk, A. and Bejan, A. (2010) Constructal Distribution of Solar Chimney Power Plants: Few Large and Many Small. International Journal of Green Energy, 7, $577-$ 592. http://dx.doi.org/10.1080/15435075.2010.529402

[2] Haaf, W., Friedrich, K., Mayr, G. and Schlaich, J. (1983) Solar Chimneys: Part I: Principle and Construction of the Pilot Plant in Manzanares. International Journal of Solar Energy, 2, 3-20. http://dx.doi.org/10.1080/01425918308909911

[3] Gannon, A.J. and Von Backström, T.W. (2003) Solar Chimney Turbine Performance. Journal of Solar Energy Engineering, 125, 101-106. (Cited on p. 33) http://dx.doi.org/10.1115/1.1530195

[4] Kirstein, C.F. and von Backström, TW. (2006) Flow through a Solar Chimney Power Plant Collector-to-Chimney Transition Section. Journal of Solar Energy Engineering, 128, 312317. http://dx.doi.org/10.1115/1.2210502

[5] Aurélio dos Santos Bernardes, M., von Backström, T.W. and Kröger, D.G. (2009) Analysis of Some Available Heat Transfer Coefficients Applicable to Solar Chimney Power Plant Collectors. Solar Energy, 83, 264-275. http://dx.doi.org/10.1016/j.solener.2008.07.019

[6] Schlaich, J. (1995) The Solar Chimney: Electricity from the Sun. Axel Menges, Stuttgart.

[7] von Backström, T.W. and Fluri, T.P. (2006) Maximum Fluid Power Condition in Solar Chimney Power Plants-An Analytical Approach. Solar Energy, 80, 1417-1423. http://dx.doi.org/10.1016/j.solener.2006.04.001

[8] Krisst, R.J.K. (1983) Energy Transfer System. Alternative Sources of Energy, 63, 8-11.

[9] Kulunk, H. (1985) A prototype solar convection chimney operated under Izmit conditions. Proceedings of the 7 th Miami International Conference on Alternative Energy Sources, Vol. 162.

[10] Pasumarthi, N. and Sherif, S.A. (1998) Experimental and Theoretical Performance of a Demonstration Solar Chimney Model-Part I: Mathematical Model Development. International Journal of Energy Research, 22, 277-288. http://dx.doi.org/10.1002/(SICI)1099-114X(19980310)22:3<277::AID-ER380>3.0.CO;2-R

[11] Pasumarthi, N. and Sherif, S.A. (1998) Experimental and Theoretical Performance of a Demonstration Solar Chimney Model-Part II: Experimental and Theoretical Results and Economic Analysis. International Journal of Energy Research, 22, 443-461. http://dx.doi.org/10.1002/(SICI)1099-114X(199804)22:5<443::AID-ER381>3.0.CO;2-V

[12] Zhou, X., Yang, J., Xiao, B. and Hou, G. (2007) Simulation of a Pilot Solar Chimney Thermal Power Generating Equipment. Renewable Energy, 32, 1637-1644. http://dx.doi.org/10.1016/j.renene.2006.07.008

[13] Duffie, A. and Beckman, A. (2013) Solar Engineering of Thermal Processes. John Wiley \& Sons, Inc., Hoboken.

[14] Koonsrisuk, A. and Chitsomboon, T. (2009) A Single Dimensionless Variable for Solar Tower Plant Modeling. Solar Energy, 83, 2136-2143. http://dx.doi.org/10.1016/j.solener.2009.07.015

[15] Krätzig, W.B. (2013) Physics, Computer Simulation and Optimization of Thermo-Fluidmechanical Processes of Solar Updraft Power Plants. Solar Energy, 98, 2-11. 
http://dx.doi.org/10.1016/j.solener.2013.02.017

[16] Calvert, J.G. (1990) Glossary of Atmospheric Chemistry Terms (Recommendations 1990). Pure and Applied Chemistry, 62, 2167-2219. http://dx.doi.org/10.1351/pac199062112167

[17] Zhou, X.P., dos S. Bernardes, M.A. and Ochieng, R.M. (2012) Influence of Atmospheric cross Flow on Solar Updraft Tower Inflow. Energy, 42, 393-400. http://dx.doi.org/10.1016/j.energy.2012.03.037

[18] Duffie, A. and Beckman, A. (2013) Solar Engineering of Thermal Processes. John Wiley \& Sons, Inc., Hoboken. http://dx.doi.org/10.1002/9781118671603

\section{Nomenclature}

\begin{tabular}{llll}
\hline$\dot{m}$ & Mass flow rate, $\mathrm{Kg} / \mathrm{s}$ & $p$ & pressure, $\mathrm{Pa}$ \\
$A$ & Flow area, $\mathrm{m}^{2}$ & $q_{\text {added }}$ & Heat added, $\mathrm{W} / \mathrm{m}^{2}$ \\
$A_{r}$ & Collector cover, $\mathrm{m}^{2}$ & $R$ & Ideal gas constant, $\mathrm{J} / \mathrm{kg} \mathrm{K}$ \\
$C_{p}$ & Specific heat capacity at constant pressure, & $T$ & Absolute temperature, $\mathrm{C}$ \\
& $\mathrm{J} /(\mathrm{kg} \mathrm{K})$ & & \\
$g$ & gravitational acceleration, $\mathrm{m} / \mathrm{s}^{2}$ & $U$ & Collector loss coefficient, $\mathrm{W} / \mathrm{m}^{2} \mathrm{C}$ \\
$I_{c h}$ & Chimney height, $\mathrm{m}$ & $h_{r}$ & Radiant heat transfer coefficient, $\mathrm{W} / \mathrm{m}^{2} \mathrm{C}$ \\
$I_{r}$ & Solar collector height, $\mathrm{m}$ & $h_{c}$ & Convective heat transfer coefficient, $\mathrm{W} / \mathrm{m}^{2} \mathrm{C}$ \\
$I$ & Solar irradiation, $\mathrm{W} / \mathrm{m}^{2}$ & $V$ & Flow velocity, $\mathrm{m} / \mathrm{s}$ \\
$X$ & Pressure ratio & $h_{W}$ & Wind heat transfer coefficient, $\mathrm{W} / \mathrm{m}^{2} \mathrm{C}$ \\
$\mathrm{Nu}$ & local average Nusselt number & $P r$ & local average Prandtl number \\
\hline
\end{tabular}

\section{Greek Symbols}

\begin{tabular}{llll}
\hline$\alpha$ & Solar collector absorption coefficient & $\beta$ & coefficient of volumetric thermal expansion, $1 / \mathrm{K}$ \\
$\gamma$ & Specific heat ratio & $\rho$ & Density, $\mathrm{kg} / \mathrm{m}^{3}$ \\
$\Delta T$ & temperature rise between ambient and & $\varepsilon$ & Emission \\
& collector outlet, $\mathrm{K}$ & & \\
$\eta_{\text {coll }}$ & The solarcollector efficiency & &
\end{tabular}

\section{Subscripts}

\begin{tabular}{llll}
\hline 1, 2, 3, 4 & position along the solar chimney (as depicted in Figure 1) & amb & Ambient \\
SCPP & Solar chimney power plant & $c-a$ & Collector to air \\
$c h$ & Chimney & $g-c$ & Ground to collector \\
coll & Solar collector & & \\
\hline
\end{tabular}


Submit or recommend next manuscript to SCIRP and we will provide best service for you:

Accepting pre-submission inquiries through Email, Facebook, LinkedIn, Twitter, etc. A wide selection of journals (inclusive of 9 subjects, more than 200 journals)

Providing 24-hour high-quality service

User-friendly online submission system

Fair and swift peer-review system

Efficient typesetting and proofreading procedure

Display of the result of downloads and visits, as well as the number of cited articles

Maximum dissemination of your research work

Submit your manuscript at: http://papersubmission.scirp.org/

Or contact jpee@scirp.org 